\title{
Uma pós-graduação em estudos sobre ciência, tecnologia e sociedade: uma proposta inclusiva
}

\author{
Renato Dagnino \\ Universidade Estadual de Campinas
}

\section{Resumo}

0 êxito das políticas de inclusão social explicitará necessidades materiais cuja satisfação vai demandar soluções tecnocientíficas originais para produção de bens e serviços em quantidade e qualidade inusitadas. Políticas públicas de natureza singular, explorando a organização do trabalho na sua produção e circulação, mediante pesquisa e disseminação de conhecimento tecnocientífico original, precisarão ser elaboradas para transformar a inclusão social numa rota alternativa de desenvolvimento. A proposta da Adequação Sociotécnica de reprojetamento da tecnologia convencional (operadas por empresas) e de desenvolvimento de tecnologia social é um vetor cognitivo para o enfrentamento desse desafio. Ele requer profissionais que o curso de pós-graduação em estudos sobre ciência, tecnologia e sociedade que se está propondo deverá formar.

Palavras-chave: Estudos sobre ciência tecnologia, sociedade. Ensino de pósgraduação. Inclusão social. Economia solidária. Adequação sociotécnica. 


\section{Postgraduate studies in science, technology and society: an inclusive proposal}

Success of social inclusion policies will make explicit material needs, whose satisfaction demands unique technoscientific solutions for production of goods and services in unusual quantity and of unusual quality. Singular Public policies will have to be developed, based on research and dissemination of original technoscientific knowledge, and exploring the organization of work during their production and circulation. This, in order to make of social inclusion an alternative path of development. The "Sociotechnical Adaptation" proposal for redesigning conventional technology loperated by private companies) and development of Social Technology is a cognitive vector adequate to face this challenge. This requires professionals, an essential element of whose training would be a postgraduate course in Science, Technology and Society Studies.

Keywords: Science, Technology and Society Studies. Postgraduate teaching. Social inclusion, solidarity economy, sociotechnical adaptation.

\section{Estudios de postgrado en ciencia, tecnología y sociedad: una propuesta inclusiva}

El éxito de las políticas de inclusión social hará explícitas las necesidades materiales cuya satisfacción exige soluciones tecnocientíficas originales para la producción de bienes y servicios en cantidad y calidad inusitadas. Políticas públicas de diferente naturaleza tendrán que ser elaboradas para aprovechar la oportunidad de organizar su producción y circulación a través de la investigación y la difusión de conocimiento tecnocientífico adecuado para transformar la inclusión social en una vía alternativa de desarrollo. La propuesta de la Adecuación Sociotécnica para rediseñar la tecnología convencional loperados por empresas privadasl y desarrollar Tecnología Social es un vector cognitivo para enfrentar este desafío. Para eso se requiere la formación de profesionales e implantar un curso de postgrado en Estudios sobre Ciencia, Tecnología y Sociedad, como elemento esencial.

Palabras-clave: Estudios sobre ciencia, tecnología y sociedad. Enseñanza de postgrado. Inclusión social, economía solidaria, adecuación sociotécnica. 


\section{Introdução}

Para que abordar o campo dos estudos sobre ciência, tecnologia e sociedade (ECTS) em nível de pós-graduação na universidade pública brasileira? Não sendo educação científica ou tecnológica para gerar profissionais capazes de desenvolver e aplicar inovações para aumentar a competitividade das empresas, para quê? Do que se trata então? É a própria abordagem dos ECTS, ou o que é também conhecido como enfoque CTS, o que nos permite uma resposta acerca de por que esse tipo de formação ou capacitação orientado para a produção de conhecimento tecnocientífico para o desenvolvimento social é hoje, principalmente em nosso país, essencial para assegurar um futuro melhor.

Este texto justifica a necessidade de dar início a um processo de formação interdisciplinar de pesquisadores e professores dos vários níveis de ensino, gestores públicos, integrantes de movimentos sociais, etc., que deverá culminar com a constituição de um potencial para geração de conhecimento tecnocientífico orientado à inclusão social.

Para trilhar o percurso argumentativo que justifica a criação de uma pósgraduação em ECTS numa universidade pública que alavanque o fortalecimento das políticas públicas orientadas à inclusão social, este texto está organizado tendo como referência os passos de uma cadeia causal estruturada mediante as seções que o compõem e que deverá ser lembrada na sua leitura.

0 texto se inicia fazendo referência às políticas de inclusão social que vêm sendo implementadas para reverter a desigualdade e argumenta seu necessário e provável fortalecimento. A seção seguinte mostra como a magnitude da exclusão social brasileira e a complexidade que, cada vez mais envolve sua redução, exige o aprofundamento das formas de produção e circulação propostas pela Economia Solidária. Na terceira é apontado como a orientação de parte do poder de compra do Estado, hoje alocado à aquisição de bens e serviços necessários para implementação das políticas públicas, poderia possibilitar sua expansão com consideráveis ganhos de eficácia e eficiência. As políticas de inclusão de novo tipo necessárias para viabilizar essas mudanças são o foco das três seções que seguem. Elas abordam de modo encadeado o seu componente tecnocientífico, a avaliação do potencial necessário para sua geração e o modo apropriado de expandí-lo. Completado o momento descritivo do quadro problemático a ser atacado, a sétima seção avança no terreno francamente normativo indicando como adaptar a forma de ensinar tecnociência na direção do desenvolvimento social a partir dos ECTS. E, desse modo, permitir a formação de pessoal nas áreas de ensino, pesquisa, extensão, planejamento e fomento, capaz de de realizar a transformação cognitiva necessária. 


\section{O necessário e provável fortalecimento das políticas públicas de inclusão social}

Nosso país ainda é um dos mais desiguais do mundo. A exclusão social atinge severamente nossa população. Milhões de pessoas, sobretudo as mais jovens, vêm sendo mantidas em situação de informalidade sem que nossa economia tenha sido capaz de absorver os que pretendem ingressar no mercado de trabalho formal.

Dados fornecidos pelo Instituto de Pesquisa Econômica Aplicada (IPEA, 2011) e pelo Instituto Brasileiro de Geografia e Estatística (IBGE, 2011) ilustram a gravidade da situação social em que o Brasil se encontra. Segundo o IPEA (2011), a parcela correspondente a $1 \%$ dos mais ricos da população (cerca de 1,7 milhões de pessoas) apropria-se de $13 \%$ do total da renda domiciliar - a mesma fração da qual se apropriam os $50 \%$ mais pobres (algo em torno de 87 milhões de pessoas).

Além disso, segundo o IBGE (2010), cerca de $47 \%$ das famílias brasileiras têm dificuldades significativas no que diz respeito ao acesso a alimentos, o que aponta para uma persistência da insegurança nutricional e alimentar no Brasil. A distribuição extremamente desigual da renda e da riqueza não é, contudo, o único constrangimento socioeconômico que tem acometido o Brasil ao longo dos últimos anos. A informalidade avaliada pela quantidade de trabalhadores sem carteira assinada em relação à população em idade ativa indica que a maioria dos seus integrantes muito dificilmente conseguirá obtê-la.

Um dos condicionantes dessa situação foi o violento processo de desindustrialização e desnacionalização ocorrido no período neoliberal. Em menos de vinte anos, de 1985 a 2004, a participação porcentual da indústria manufatureira no PIB caiu 36\%. Entre 1985 e 2004, o tripé capital estrangeiro, privado nacional e estatal, tomando as 500 maiores empresas, que era de $29 \%, 41 \%$ e $31 \%$, passou a ser $46 \%, 35 \%$ e $20 \%$. Em apenas meia década o capital estrangeiro cresceu $60 \%$, o privado nacional diminuiu $50 \%$ e o estatal diminuiu $35 \%$. Mudou também, significativamente, o tipo de inserção do País na economia mundial. 0 período que vai de 1990 a 2000 é revelador de uma tendência que se mantém, aprofundando-se, até hoje. Nele, o coeficiente de importação/consumo do setor industrial cresceu de 6 a $15 \%$, o do segmento de material de transporte passou de 5 a $23 \%$ e o de eletroeletrônicos de 10 a $66 \%$. A relação entre o investimento em bens de capital e o PIB, que havia alcançado $27 \%$ em 1989, decresceu para $20 \%$ em 2005 luma diminuição de $35 \%$ ). As consequências se fizeram sentir também na importação de tecnologia (licenciamento, patentes).

Somos atualmente 204 milhões, e mais de 160 milhões em idade ativa. Partindo dos 28 milhões de empregos formais existentes no fim do governo neoliberal, 
conseguimos chegar a quase 45 milhões. Nos últimos doze anos, o emprego formal absorveu 1,5 milhão de pessoas por ano.

Mesmo sem considerar que $93 \%$ delas recebem menos de três salários mínimos, esta taxa é incapaz de absorver os mais de 2 milhões que se somam aos que, anualmente, buscam no setor formal alguma oportunidade de viver dignamente. É importante frisar que nesse período muitos fatores contribuíram para ativar a economia e gerar emprego formal: extensão da Previdência, Bolsa Família, aumento do salário mínimo, aumento das exportações de bens primários e alimentos.

A inclusão social daqueles que hoje estão à margem do sistema socioeconômico é uma evidente prioridade. Para tratar o tema, é necessário precisar que ela é aqui entendida como um processo que permitiria aos excluídos buscar oportunidades de "trabalho e renda" lque é a consigna hoje veiculada pelo movimento da Economia Solidárial que substituam a promessa do neodesenvolvimentismo do "emprego e salário". Atividades produtivas que, em função das limitações que vem apresentando a esfera econômico-produtiva formal, deverão ter sua realização cada vez mais concentrada no que se tem denominado no Brasil de Economia Solidária.

A inclusão tem, ainda, dimensão complementar importante, embora sutil. Trata-se da dimensão política e cultural, entendida como a participação plena e de forma ativa de todos os cidadãos nos processos que ocorrem na sociedade; inclusive naqueles de natureza cognitiva. Participação que dificilmente ocorrerá na economia formal devido à magnitude que alcançou a exclusão social em nosso país e ao provável aprofundamento dos processos globais associados à "economia com crescimento sem geração de emprego" (jobless growth economy) e à "economia com crescimento que elimina certos tipos de emprego" (jobloss growth economy).

\section{Políticas de inclusão de novo tipo e a Economia Solidária}

Trabalhadores hoje situados na economia informal não tenderão a ser incorporados à economia formal da qual foram excluídos, , ou na qual nunca estiveram efetivamente incluídos. Essa tendência contraria a expectativa já de quase meio século, mas ainda na moda - de autores seminais da Teoria de Desenvolvimento Econômico, como Lewis (2003) e Rostow (1960), ainda implicitamente invocados para explicar a existência de um setor atrasado nas economias em desenvolvimento passível de ser absorvido pelo seu setor moderno industrializado que seria responsável pelo progresso econômico e social.

A escassa probabilidade de sucesso da proposta neodesenvolvimentista, por 
um lado, desloca o desafio produtivo da inclusão social da economia formal para a Economia Solidária. Por outro, implica que se considere que o processo de inclusão social seguirá colocando em destaque necessidades que, para serem satisfeitas, demandarão a produção de bens e serviços em quantidade e qualidade inusitadas, com formas de produção e conhecimento tecnocientífico também originais. 0 que supõe que algumas das atividades de produção de bens e serviços, usualmente realizadas por empresas que crescentemente são transferidas de modo precarizado para o setor informal, possam ser levadas a cabo por empreendimentos solidários.

À luz do cenário que se configura para os próximos anos, é provável que as políticas públicas orientadas à inclusão social venham a estar cada vez mais focadas para além do meramente compensatório, de modo a fortalecer seu caráter de "porta de saída" à exclusão baseada na criação de oportunidades de "trabalho e renda"; o que torna especialmente oportuno e necessário o argumento desenvolvido neste texto: a necessidade de incluir os ECTS no ensino de pósgraduação.

\section{Economia Solidária e poder de compra do Estado}

O êxito de políticas socialmente inclusivas torna necessário completar, adensar e interligar cadeias produtivas hoje situadas na economia informal ou que possam ser implantadas na Economia Solidária. Um cenário - futuro - desejável seria um que privilegiasse a satisfação das necessidades materiais dos hoje excluídos, que serão incluídos ao se incorporar, não na economia formal, mas na Economia Solidária, mediante atividades ali realizadas. Para tanto, elas terão que ser alvo de apoio estatal; que não tem porque se dar de modo menos incisivo do que o proporcionado às empresas privadas mediante subsídios de diversas naturezas.

Atividades hoje realizadas por outros agentes econômicos, em geral empresas privadas, que produzem bens e serviços adquiridos pelo Estado para satisfazer mediante a implementação das políticas a grande e variada demanda por bens públicos que ele deve proporcionar a todos os cidadãos, poderão ser levadas a cabo pelos empreendimentos solidários. 0 Estado poderia, então, satisfazer essa demanda reorientando seu poder de compra, hoje canalizado quase que exclusivamente para as empresas (que empresa não gostaria de contar com a reprodução e a escala das compras governamentais?), para alavancar a "inclusão produtiva". É claro que esse movimento terá que ser parcial, dado que sujeito à relação de forças políticas existente na sociedade, e paulatino, uma vez que dependente do aumento da capacidade tecnocientífica e organizativa daqueles 
empreendimentos.

O modo como hoje se aloca o poder de compra do Estado não contribui, como poderia, para gerar impactos que potencializem o esforço que o próprio governo vem fazendo no campo da inclusão social e, inclusive, da Economia Solidária. Dos quase $40 \%$ do PIB que arrecada, quase a metade é gasto comprando das empresas os bens e serviços (transporte, energia, educação, saúde, segurança, comunicação, habitação etc.) que chegam aos cidadãos por meio das políticas públicas em troca dos impostos que pagam.

0 "Minha casa minha vida”, por exemplo, alocou $97 \%$ dos recursos às empreiteiras (que estão entre as que mais corrompem), quando $54 \%$ das casas brasileiras são construídas pelos seus moradores le entre os mais pobres, provavelmente, $100 \%$ ). Oportunidades de geração de trabalho e renda, mobilizando outros agentes econômico-produtivos por meio da utilização do poder de compra do Estado, deverão ser implementadas à medida que forem sendo exorcizados os fantasmas da governabilidade que rondam nossa democracia.

Potencializar a geração de trabalho e renda mediante a produção de bens públicos é algo que já está ocorrendo: uma iniciativa exemplar é a que faz com que as prefeituras adquiram $30 \%$ da alimentação escolar da agricultura familiar.

Orientar as compras públicas para empreendimentos que operem em redes de Economia Solidária e com tecnologia social, em unidades de pequena escala, autogestionárias, com propriedade coletiva dos meios de produção e pouco demandantes de qualificação formal, é a forma de multiplicar o impacto das políticas de inclusão social existentes.

\section{0 componente tecnocientífico das políticas de inclusão de novo tipo}

Avançando um passo mais na cadeia argumentativa proposta se aborda agora o elo cognitivo que permitirá conectar a tendência inclusiva em curso com o ensino CTS.

A sustentabilidade econômica, cultural e ambiental dos empreendimentos solidários demanda formas de produção de bens e serviços distintas daquelas desenvolvidas pelas e para as empresas.

Problemas de natureza tecnocientífica originais e de alta complexidade, dadas as severas restrições de sustentabilidade existentes e a necessidade de abordagem interdisciplinar e transversal, terão que ser atacados pelo complexo público de universidades e institutos de pesquisa com a participação de atores - os empreendimentos solidários - até agora pouco presentes nesse cenário. 
0 desenvolvimento do conhecimento tecnocientífico que esses arranjos produtivos necessitam terá que ser apoiado de modo distinto daquele usado para fomentar atividades de P\&D realizadas pelas e para as empresas. Situadas no foco da política de ciência, tecnologia e inovação, elas vêm recebendo, há muito tempo, vultoso, variado e continuado apoio estatal. 0 apoio aos empreendimentos solidários demanda novos modos de regulação da transferência de recursos e orientação do poder de compra do Estado para a gama crescente de bens e serviços que eles podem produzir.

Dado o ineditismo e as dificuldades associadas ao objetivo que se pretende realizar, pode-se depreender que será impossível concretizá-lo sem o envolvimento dos profissionais da educação e da pesquisa tecnocientífica. A viabilização do processo de inclusão social fará com que formas de organização da produção e do trabalho tenham que ser concebidas, mediante o reprojetamento da tecnologia convencional das empresas e a elaboração de políticas de natureza singular. Desafios cognitivos para cujo enfrentamento pouco serve a tecnociência capitalista que até agora desenvolvemos, reproduzimos e ensinamos no complexo público de universidades e institutos de pesquisa institutos de pesquisa, terão que ser efrentados. E isso será muito mais difícil do que seguir a tendência hegemonizada pelas empresas transnacionais que hoje é responsável pela metade da pesquisa realizada no mundo.

Processos de reprojetamento de tecnologias existentes, mas não adaptadas à dramática realidade de uma economia informal em trânsito para uma Economia Solidária, e a geração de conhecimento novo mediante uma exploração da fronteira tecnocientífica com um viés distinto ao daquelas empresas, tudo isto em consonância com os princípios da solidariedade, da propriedade coletiva e da autogestão terá que ser realizado pelos nossos professores e pesquisadores. E com a participação de integrantes de empreendimentos solidários, condição indispensável para o êxito de uma empreitada nunca antes alcançada.

\section{Avaliando o potencial de geração de conhecimento tecnocientífico para políticas de inclusão de novo tipo}

O Brasil tem conseguido nas últimas décadas, como resultado de um gasto público consistente e continuado, consolidar sua estrutura tecnocientífica. Isso tem ocorrido de forma assimétrica. 0 conhecimento que tem sido produzido, seja na sua forma incorporada em pessoas, seja desincorporada, possui um potencial de aplicação enviesado no sentido da satisfação das demandas 
cognitivas das empresas. Tem sido quase nula a atenção dedicada aos campos que, de forma direta ou indireta, apresentam potencial significativo para a promoção da inclusão socioprodutiva.

Ao contrário do que ocorre com as ações da PCTI orientadas ao objetivo da competitividade empresarial, que buscam sinergia com as políticas industrial e agrícola, de comércio exterior, etc., as atinentes ao desenvolvimento social sofrem de uma debilidade crônica. Como resultados, tem-se uma grande escassez de pessoal qualificado para atuar de modo sinérgico no plano do ensino, pesquisa, planejamento e fomento, visando à construção de um aparato institucional orientado à inclusão social.

Isto não surpreende, tendo em vista que essas atividades no âmbito do MCTI são muito mais recentes e que têm recebido recursos relativamente insignificantes. Um resultado dessa situação a ser destacado, tendo em vista o objetivo deste texto, é que não tem existido, ao contrário do que ocorre com aquelas, um esforço sistemático de formação de pessoal com o perfil e na quantidade necessários.

A compreensão da relação entre a tecnociência e a exclusão e potencial inclusão pouco avançou até pouco tempo atrás. Apesar do discurso da PCTI elaborada desde a década de 1960 ter feito sucessivas referências ao desenvolvimento social nunca houve uma cultura institucional capaz de gerar o conhecimento capaz de materializá-lo. Uma decisão mais palpável de capacitar profissionais e apoiar a pesquisa tecnocientífica para a inclusão social só ocorreu em 2003, no âmbito da equipe de transição para o Governo Lula, quando se cogitou criar um mecanismo institucional com essa finalidade. 0 que veio a ocorrer com a criação da Secretaria de Ciência e Tecnologia para a Inclusão Social no então Ministério da Ciência e Tecnologia e, posteriormente, com a formalização de uma "Linha de Ação Capacitação em Ciência e Tecnologia para - Desenvolvimento Social" num dos quatro eixos do Plano de Ação de Ciência e Tecnologia (2007-2010).

A existência de uma meta de política denotada por essa linha de ação, embora indicasse a necessidade de formação de pessoal com essa finalidade, não foi suficiente para desencadear as ações apropriadas para materializá-la. Uma das dificuldades enfrentadas foi o fato de que ações de capacitação com essas características nunca haviam sido realizadas no País e que não existam antecedentes desta natureza nno plano internacional. 0 que implicava le ainda implical a necessidade de romper uma espécie de círculo vicioso formando docentes e pesquisadores e, inclusive, gestores capazes de atuar para a promoção de conexões entre as políticas de C\&T e de desenvolvimento social, visando à inclusão socioprodutiva. 


\section{Expandindo o potencial de geração de conhecimento tecnocientífico para políticas de inclusão de novo tipo}

Um espaço que pode cumprir com esse objetivo vem surgindo na área de Extensão das universidades públicas e vem se materializando nas Incubadoras Tecnológicas de Cooperativas Populares. A expansão do sistema de educação profissional e tecnológica, cuja missão sinaliza para a intervenção junto a agentes tecnoprodutivos que guardam alguma relação com os empreendimentos solidários, é também auspiciosa.

Um movimento de ampliação desse espaço, mediante a incorporação de segmentos da comunidade universitária sensíveis à proposta da inclusão socioprodutiva e sua consolidação, mediante a obtenção de recursos externos e internos à universidade, permitirá induzí-los a mobilizar seu potencial de ensino e pesquisa para iniciar ações visando à sustentabilidade econômica, cultural e ambiental aos empreendimentos solidários. E, no médio prazo, permitirá capacitar profissionais na perspectiva dos ECTS de maneira a desencadear um processo que propicie a fundamentação analítico-conceitual e metodológico-operacional para levar a cabo a expansão dessas ações de modo autossustentado e cada vez mais abrangente.

Um movimento buscado será a paulatina transformação do código técnico do pessoal envolvido em atividades de pesquisa e desenvolvimento nas empresas estatais, , universidades e institutos de pesquisa públicos. Ele é atualmente orientado segundo os interesses e valores da empresa privada, que são os hegemônicos na conformação da dinâmica global de produção e difusão do conhecimento tecnocientífico, que abarca desde o desenvolvimento da hi-tec do complexo científico-industrial-militar até o ensino pré-universitário na periferia do sistema capitalista. 0 objetivo é orientá-lo segundo outro viés: o do desenvolvimento social. Esse movimento, ao mesmo tempo consequência e causa retroalimentadora da transformação buscada irá complementar a formação dos novos profissionais que estarão sendo educados, segundo o marco analítico-conceitual dos ECTS e familiarizados com os instrumentos metodológico-operacionais que irão sendo concebidos.

0 resultado desses dois movimentos será a introdução de conceitos, critérios, variáveis, relações, fatos estilizados, modelos, algoritmos na "planilha de cálculo" dos novos profissionais. Estes serão responsáveis por garantir a transformação cognitiva que demanda a inédita experiência de radicalização da democracia com desenvolvimento social protagonizada por um número crescente de países latinoamericanos. 


\section{Adaptando a forma de ensinar tecnociência na direção do desenvolvimento social}

Colocada a problemática traduzida na necessidade de formar pessoal nas áreas de ensino, pesquisa, extensão, planejamento e fomento capacitado a realizar a transformação cognitiva buscada, cabe passar ao momento normativo da "solucionática".

Limitando como corresponde o escopo dessa preocupação à universidade pública, a pergunta que orienta o raciocínio é relativa ao corpo de conhecimento capaz de orientar essa formação. Em particular, como orientar a educação e a pesquisa universitária no sentido desejado, na perspectiva dos ECTS?

Responder a pergunta demanda uma digressão histórica que nos leva aos países de língua inglesa que desenvolveram o campo Science, Technology and Society nas suas universidades a partir da década de 1970. Movimentos que tiveram origens distintas, segundo a realidade dos diferentes países em que ocorreram, mas que tinham como matriz comum o questionamento do ufanismo e do triunfalismo da tecnociência, foram se originando, entre outros âmbitos, nas carreiras de ciências duras (naturais, exatas e engenharias). No caso dos países europeus, foram professores e pesquisadores dedicados às ciências sociais que já possuíam um espaço dedicado à análise da ciência ou da tecnologia (sociologia, antropologia, história e filosofia da ciência, etc.) os que se dedicaram às pesquisas que originaram o campo.

Nos EUA, a origem do movimento CTS, que derivou nos ECTS, foi a pressão social contra a utilização dos resultados da pesquisa pública para fins militares durante a guerra do Vietnã e para a fabricação de produtos que ameaçavam a segurança do consumidor, além da preocupação ambiental então nascente.

Mas foi na América Latina, no final da década de 1960, que aparece a abordagem ao assunto que parece ser a mais interessante para responder à pergunta acima formulada. Ela nasceu da preocupação de pesquisadores das ciências duras que, principalmente na Argentina - país que na época concentrava a maior parte do potencial tecnocientífico da região -, insatisfeitos com o fato de que o resultado de seu trabalho não estava encontrando aplicação prática. Dado que essa situação impedia que levassem adiante sua atividade de pesquisa, eles começaram a discutila no efervescente e nacionalista ambiente universitário. Seu viés era bastante distinto do europeu, de natureza acadêmica, e do estadunidense, preocupado com questões políticas não imediatamente relacionadas à universidade. Inauguraram o que foi posteriormente denominado Pensamento Latino-americano em Ciência, Tecnologia e Sociedade (PLACTS) (Dagnino, Thomas e Davyt, 1996). Por atribuírem a causa do problema à escassa demanda social por conhecimento autóctone, e 
considerarem que, enquanto não fosse gestado um Projeto Nacional intensivo em conhecimento tecnocientífico, ele não seria resolvido (Herrera, 1975), seu trabalho seguiu uma orientação distinta, relacionada às políticas mpubas (policy). Tendo como marco analítico-conceitual as contribuições da Cepal e da Teoria da Dependência, eles focaram sua atenção em aspectos atinentes à relação entre a política científica e tecnológica e as demais políticas públicas, buscando orientála de modo distinto daquele dos países de capitalismo avançado. Isto é, para enfrentar os condicionantes socioeconômicos do subdesenvolvimento da região.

Apesar da preocupação com o tema ter surgido na mesma época, as primeiras iniciativas sistemáticas de pesquisa e formação de profissionais em nível de pósgraduação no campo dos ECTS ocorreram aqui bem depois do que nos países avançados. Fatores de natureza interna à universidade e associados ao contexto político latino-americano levaram a que só no início da década de 1980 elas surgissem, quando já estavam consolidados programas similares nos EUA e na Europa, no Centro de Estudios del Desarrollo (Venezuela), na Universidade Estadual de Campinas (Brasil) e na Universidade de Buenos Aires (Argentina). Às iniciativas pioneiras no Brasil em nível de graduação, como as das universidades Federal de Santa Catarina e Estadual de Campinas, seguiram-se outras em diversas universidades da região que passaram em alguns casos a incluir o nível da pósgraduação.

Também na década de 1980 surgia na Espanha, e se irradiava para os países latino-americanos de língua espanhola, uma preocupação sistemática com os ECTS, que encontrou no âmbito da Organização de Estados Ibero-americanos um importante apoio institucional. Em função dos desdobramentos havidos na América Latina, assistimos hoje à produção de considerável literatura acerca do ECTS cuja orientação encontra-se mais alinhada com essa última perspectiva e com a dos centros dos países de capitalismo avançado do que com aquela proposta pelo PLACTS.

Essa digressão, embora breve, é suficiente para mostrar o potencial de cognitivo os ECTS passível de ser mobilizado para preencher a lacuna relativa à geração de conhecimento para a inclusão social. Por englobar pelo menos duas dimensões, ela demanda um ataque em duas frentes de trabalho.

A primeira, de importância evidente, ainda que menos original, pode ser considerada como uma de suas atividades-fim. Trata-se das atividades desenvolvidas por equipes universitárias nas áreas de agricultura familiar, habitação popular, energias alternativas, reciclagem de resíduos, produção e conservação de alimentos, saneamento de baixo custo, entre muitas outras. Integrantes dessas equipes (professores, pesquisadores, alunos, gestores), preocupados em fazer com que o conhecimento que possuem possa ser orientado 
para a inclusão social, têm-se conectado a movimentos sociais que lutam pelo acesso dos excluídos aos direitos de cidadania e que, para isto, demandam as tecnologias alternativas que eles se consideram aptos a desenvolver.

Apesar de suas intenções, os integrantes dessas equipes não têm atentado de modo adequado para o conteúdo socialmente construído da ciência (Bloor, 1991) e da tecnologia (Bijker, Hughes e Pinch, 1989; Bijker, 1995;) que vem sendo tratado desde a década de 1970 pelos pesquisadores dos ECTS. Isto é, para o fato de que elas são o resultado de uma contínua negociação sociotécnica entre diferentes atores sociais. Os quais como salientam alguns autores (Feenberg, 2002) podem possuir projetos políticos antagônicos. E que, por isto mesmo, muito mais do que resultados da aplicação do "método científico" ou da busca da "eficiência técnica", refletem e trazem embutidos os valores e interesses dominantes nos ambientes em que são produzidas (Dagnino, 2008.)

Interesses que os integrantes dessas equipes, paradoxalmente, percebem como contrários ao desenvolvimento social e à sustentabilidade ambiental que desejam. E que se opõem aos seus próprios interesses como trabalhadores lque hoje trabalham mais tempo e com crescente desgaste vital), como consumidores (bombardeados com produtos de serventia e qualidade duvidosas ao mesmo tempo que se degradam os bens e serviços relacionados com sua qualidade de vidal e como habitantes de um planeta (que vem dando sinais claros de que a tecnociência que praticam e os interesses que as orientam tendem a levar à sua ruína).

A dimensão e profundidade da transformação cognitiva que terá que ocorrer no âmbito dessas equipes faz com que ela não possa ser concebida em termos da taxonomia convencional - Docência, Pesquisa e Extensão - nem mediante ações adstritas a cada um desses campos. de fato, um aspecto que vem se explicitando na trajetória das equipes orientadas na perspectiva mais radical - da Tecnologia Social (Dagnino, 2014) - é o de que aquela transformação, que eles já vêm impulsionando, tende a ser inviabilizada pelo modelo de formação de cientistas, engenheiros e outros profissionais envolvidos com a produção de conhecimento tecnocientífico.

Será um desafio permanente desta primeira frente de trabalho substituir a ideia ingênua e ineficaz da "oferta" ou "transferência" de conhecimento tecnocientífico (ou de tecnologia), que ainda predomina na esfera da Extensão universitária, por aquela oriunda da construção coletiva de conhecimento de forma não-excludente, com a incorporação dos valores, interesses e saberes dos excluídos, e orientada a aplicações produtivas passíveis de serem encadeadas mediante empreendimentos solidários apoiados pelo Estado.

0 enfrentamento desses desafios cognitivos encontra uma contribuição, na 
abordagem da Adequação Sociotécnica (Dagnino, 2014), cuja origem se deve à aplicação do enfoque CTS proporcionado pelos ECTS ao objetivo de desenvolver alternativas à tecnologia convencional. Concebida para analisar as implicações cognitivas das demandas sociotécnicas e materiais associadas a movimentos de democratização política e econômica, ela oferece uma tipologia de sete modalidades de trânsito (ou Adequação Sociotécnica) da tecnologia convencional desenvolvida pelas e para as empresas na direção da Tecnologia Social. Ao focalizar o conhecimento que necessitam os empreendimentos solidários essa abordagempode ser usada para conceber estratégias de pesquisa e ensino em ambientes receptivos aos princípios da Economia Solidária.

A segunda frente de trabalho, embora menos evidente, é mais original. Ela não poderia ser atacada se não existissem as atividades de pesquisa, docência e extensão realizadas pelas equipes já mencionadas. Isso porque, inclusive, é a partir delas, do conhecimento e experiência que acumularam, que é possível concebêla. Essa segunda frente, cujo propósito pode ser considerado uma atividade-meio, facilitadora da atividade-fim que essas equipes, com as deficiências conceituais e metodológicas apontadas, já realizam, tem a ver com a transformação cognitiva aludida. Como é frequente, ela surge depois que se explicitam as preocupações derivadas da insatisfação dos atores diretamente envolvidos le aqui a lembrança do nascimento do PLACTS é ilustrativa).

As atividades a que se faz referência são justamente as de formação de pessoal que terão que ser realizadas por aquelas equipes que são o embrião da mudança desejada. Atividades que irão produzir e disseminar junto a estudantes de pós-graduação das universidades públicas o marco analítico-conceitual e os instrumentos metodológico-operacionais necessários para prospecção e satisfação de demandas cognitivas colocadas pelo objetivo da inclusão social. 0 que terá que ocorrer mediante metodologias de trabalho especialmente concebidas para combinar capacidades e esforços (novos ou já existentes) e, assim, aumentar a eficácia, escala e abrangência daquelas equipes.

\section{Considerações finais}

A PCT brasileira não se encontra suficientemente articulada às políticas sociais. Muito menos àquelas que se orientam, segundo a perspectiva aqui indicada, da inclusão social dos excluídos à Economia Solidária. Ainda menos àquelas que visam a atender as demandas materiais de natureza coletiva ou pública, como transporte, comunicação, saneamento, educação, saúde, habitação, urbanismo, por intermédio da sua produção em empreendimentos 
solidários. Isso apesar de elas serem hoje crescentemente veiculadas por movimentos que representam os setores subalternos de nossa sociedade, cuja capacidade de organização e reivindicação vem aumentando e sendo crescentemente percebida como socialmente legítima.

Uma consequência dessa escassa articulação é que as ações que buscam concretizar o esforço que realiza o País, visando "ensinar a pescar" os que já “receberam o peixe", por meio de políticas compensatórias, encontram obstáculos que diminuem as chances de sua adequada execução. Entre eles, está o fato de que as políticas sociais, em geral, não são entendidas pelos gestores, governantes e políticos, encarregados de sua formulação, como passíveis de serem potencializadas mediante a incorporação de conhecimento tecnocientífico distinto do que costuma resultar da P\&D empresarial. Por isso, esses gestores deverão ser, também, alvo dos programas de pós-graduação em ECTS que irão impulsionar o conhecimento tecnocientífico desenvolvido mediante abordagens como as da Adequação Sociotécnica.

A dimensão do conhecimento tecnocientífico da inclusão social é estratégica para nosso futuro e também, numa perspectiva mais ampla, mas coerente com a proposta que o anima, para um futuro global sustentável. A transformação que implica essa dimensão demanda uma política cognitiva lque integrará entre outras as de educação e de C\&T) coerente com os valores e interesses que orientam a construção desse futuro. Reeditando outros momentos de inflexão socioeconômica e política, a situação presente aponta, não por casualidade, para aqueles que se identificam com a agenda dos que se encontram excluídos. Satisfazer suas necessidades materiais e, também, a variada e larga demanda por bens públicos que o Estado proporciona a todos os cidadãos lo que exige a utilização do seu poder de compra atualmente focado nas empresas) é o caminho que assinala nosso caminho na direção desse futuro. Fazer com que as atividades envolvidas sejam realizadas com maior efetividade, eficácia, sustentabilidade cultural e responsabilidade ambiental, e até eficiência, com benefícios de várias naturezas para o conjunto da sociedade e com a vantagem adicional de proporcionar àqueles empreendimentos crescente autonomia em relação à economia formal (vale a esta altura enfatizar, capitalista), é o cenário a construir (Dagnino, 2014a.)

E é com a intenção de que tudo isso se torne realidade que aqui se formula esta proposta de "Uma pós-graduação em estudos sobre ciência, tecnologia e sociedade". 


\section{Referências}

BIJKER, Wiebe. Of bicycles, bakelites, and bulbs: toward a theory of sociotechnical change. Massachusetts: The MIT Press, 1995.

BIJKER, Wiebe; HUGHES, Thomas; PINCH, Trevor. The social construction of technological systems. Massachusetts: The MIT Press, 1989.

BLOOR, David. Knowledge and Social Imagery, 2ndedn. Chicago: University of Chicago Press, 1991/1976.

IBGE. Instituto Brasileiro de Geografia e Estatística (2010) Censo Nacional.: Disponível em: <http://www.censo2010.ibge.gov.br/>. Acesso em: 20 maio 2014. IPEA. Instituto de Pesquisa Econômica e Social. Comunicado do Ipea no. 111. Disponível em: <http://www.ipea.gov.br/agencia/images/stories/PDFs/ comunicado/110915_comunicadoipea111.pdf >. Acesso em: 20 maio 2014.

BRASIL. MCTI - Ministério da Ciência, Tecnologia e Inovação. Plano de Ação 20072010. Disponivel em: <http://www.mct.gov.br/upd_blob/0021/21439.pdf>. Acesso em: 20 maio 2014.

DAGNINO, Renato. Neutralidade da ciência e determinismo tecnológico: um debate sobre a tecnociencia. Campinas: Editora Unicamp, 2008.

Tecnologia social: contribuições conceituais e metodológicas. Eduepb e Insular. Florianópolis, 2014.

.Trabalho para orientação do Painel Sociedade do Conhecimento e Educação Superior do Fórum Latino-americano de Educação Superior. Foz do Iguaçu, 17 a 18 de novembro de 2014 a.

DAGNINO, Renato; THOMAS, Hernan; DAVYT, Amilcar. El pensamiento en Ciencia, tecnología y sociedad en América Latina: una interpretación política de su trayectoria, REDES, v.3, n.7. 1996.

FEENBERG, Andrew. Transforming technology: a critical theory revisited. Oxford: Oxford University Press, 2002.

HERRERA, Amilcar 'Los determinantes sociales de la política científica em América Latina. Política científica explícita y política científica implícita'. In: SABATO, Jorge. El pensamiento latinoamericano en la problemática ciencia - tecnologia - desarrollo dependencia. Buenos Aires: Paidós, 1975.

LEWIS, William Arthur. The theory of economic growth. London: Taylor and Francis, 2003.

ROSTOW, Walt Whitman. The stages of economic growth: a non-communist manifesto. Cambridge University Press, 1960. 
Recebido em julho de 2014

Aprovado em fevereiro de 2015

Renato Dagnino é engenheiro e estudou ciências humanas e economia no Chile e no Brasil, onde se doutorou. Realizou pós-doutorado na Universidade de Sussex, Inglaterra. É professor titular na Universidade Estadual de Campinas. E-mail: rdagninolaige.unicamp.br 